\title{
Photoluminescence from SWCNT/Cu Hybrid Nanostructure Synthesized by a Soft Chemical Route
}

\author{
Rima Paul and Apurba Krishna Mitra \\ Nanoscience Laboratory, Department of Physics, National Institute of Technology Durgapur, West Bengal, Durgapur 713209, India \\ Correspondence should be addressed to Rima Paul, rimanitdgp@yahoo.com
}

Received 27 November 2011; Accepted 26 December 2011

Academic Editors: D. Y. Kim, J. McGinty, G. Montemezzani, and D. Poitras

Copyright ( $) 2012$ R. Paul and A. K. Mitra. This is an open access article distributed under the Creative Commons Attribution License, which permits unrestricted use, distribution, and reproduction in any medium, provided the original work is properly cited.

We report a simple wet chemical technique to coat single wall carbon nanotubes (SWCNTs) with Cu nanoparticles. The SWCNT/Cu hybrid nanostructure has been characterized using field emission scanning electron microscopy (FESEM), highresolution transmission electron microscopy (HRTEM), energy dispersive X-ray analysis (EDAX), X-ray diffraction (XRD) study, and Raman spectroscopy. Characteristic optical properties of the nanohybrid structure have been identified through UV-Vis and photoluminescence (PL) spectroscopy. When excited by a radiation of $400 \mathrm{~nm}$ wavelength, PL emission in the visible range of 480-620 nm was observed due to charge transfer. This property may be exploited in photovoltaic cells, solar energy conversion, and sensor devices.

\section{Introduction}

Carbon nanotubes (CNTs), with their exceptional electrical, mechanical, and optical properties [1-3], have drawn much attention of the researchers in the field of nanotechnology. On the other hand nanoparticles have attracted the researchers because of their unique chemical and physical properties $[4,5]$. CNTs hybridized with metal nanoparticles bring forth a new class of nanostructured materials into focus [6-8] because of their unique resultant physical properties. Such CNT/metal nanohybrid materials find wide application in sensor devices [9], as catalysts for fuel cells [10, 11], in solar cells $[12,13]$, as fillers $[14,15]$, and so forth. Composites of metal nanoparticles and CNTs have been synthesized by various techniques, which include direct coating or deposition on CNTs of metal nanoparticles, such as $\mathrm{Ag}, \mathrm{Au}, \mathrm{Cu}, \mathrm{Pd}$, and Pt. Several methods such as solid-state reactions, capillary action, radiolysis, physical evaporation, electroless deposition, physisorption, self-assembly, and colloidal chemistry combined with electrostatic interactions or with sonication in aqueous solution [16] have been adopted. Zhang et al. [17] fabricated carbon nanotubes with totally filled $\mathrm{Cu}$-nanowires by methane decomposition using $\mathrm{Cu}$ microgrid as a catalyst. Reddy et al. [16] developed a new method for the synthesis of $\mathrm{Cu}_{2} \mathrm{O}$-coated multiwall carbon nanotubes (MWCNTs) on the basis of Fehling's reaction. Fabrication of MWCNT-reinforced Cu matrix composite for heat sink application was reported [18]. But only a few reports have been made on simple and efficient routes for strongly attaching noble metal nanoparticles or nanospheres to CNTs $[19,20]$. Decoration of SWCNTs with extremely tiny (2-3 nm) monodispersed noble metal nanoparticles by costeffective lucid chemical process is still a challenging task [21]. Here, we report a simple wet chemical process to decorate SWCNTs with $\mathrm{Cu}$ nanoparticles of average size $3 \mathrm{~nm}$ using hexadecyltrimethylammoniumbromide (HTAB) as reducing agent. A detailed study of the optical characteristics and photoluminescence properties of the synthesized samples has been undertaken for application in various devices.

\section{Experimental Details}

SWCNTs (1-2 nm outer diameter, length: $1-3 \mu \mathrm{m}$ and purity $>95 \%$ ) were procured from Chengdu Organic Chemicals Co. Ltd., Chinese Academy of Sciences, and further purified following a chemical process [22, 23] for impurities like traces of catalyst materials and other carbon products. The purification process included heating in a muffle furnace at 


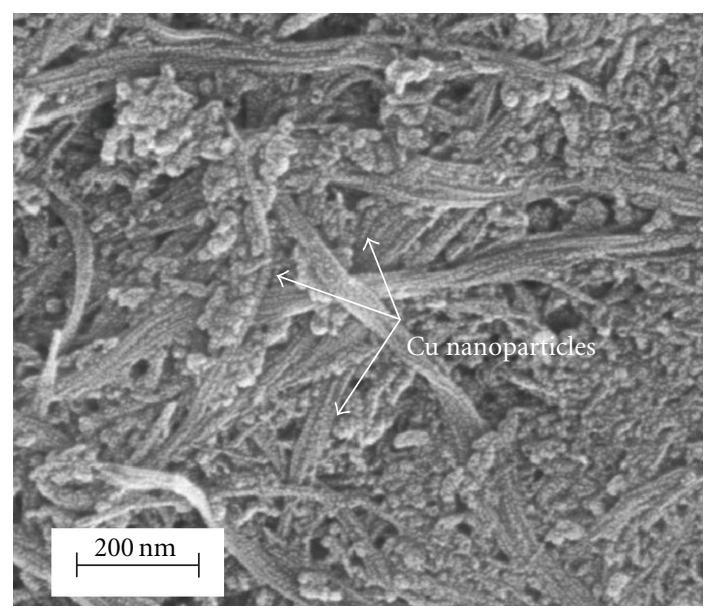

FIGURE 1: FESEM micrograph of SWCNT/Cu nanohybrid material.

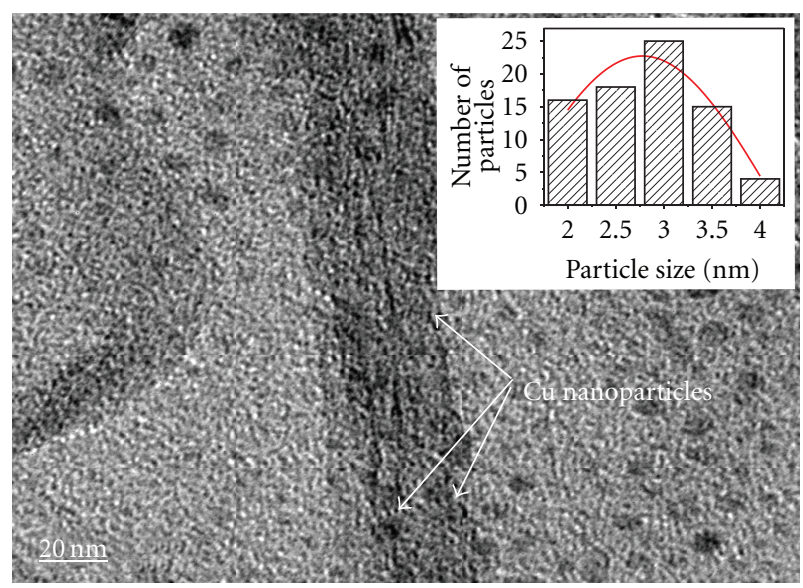

FIGURE 2: HRTEM micrograph of SWCNT/Cu nanohybrid material; inset shows the particle size distribution of $\mathrm{Cu}$ nanoparticles.

$350^{\circ} \mathrm{C}$ and soaking in $6 \mathrm{M} \mathrm{HCl}$ overnight, followed by sonication, filtration, and washing thoroughly in deionized water until $\mathrm{pH}$ became neutral. Purified SWCNTs were treated with $\mathrm{HNO}_{3} / \mathrm{H}_{2} \mathrm{SO}_{4}$ in the ratio $1: 3$ and stirred for $36 \mathrm{~h}$. The acid-treated SWCNTs were washed thoroughly with water followed by filtration using Millipore filtration apparatus. Due to acid treatment, carboxylic acid groups were attached to the defect sites of the SWCNTs. To prepare the SWCNT/Cu nanohybrid material, we added $164 \mathrm{mg}$ of $\mathrm{Cu}$ (II) nitrate in $40 \mathrm{~mL}$ of 2-propanol and sonicated for 2 min using $250 \mathrm{~W}$ piezo-U-sonic ultrasonic cleaner. $478 \mathrm{mg}$ of acid-treated SWCNTs was poured to $20 \mathrm{~mL}$ of the previous solution and stirred for $30 \mathrm{~min}$ using a magnetic stirrer (REMI 2MLH). Simultaneously, to $60 \mathrm{~mL}$ 2-propanol, $1000 \mathrm{mg}$ of HTAB was added and stirred for $30 \mathrm{~min} .30 \mathrm{~mL}$ of the freshly prepared solution was added to the solution containing SWCNTs and stirred for $30 \mathrm{~min}$. The resultant solution was then filtered using Millipore filtration apparatus, washed thoroughly with deionized water, and left for drying at room temperature.

For its nanostructural property study, characterization of the as-prepared sample was done by FESEM (Carl Zeiss Ultra

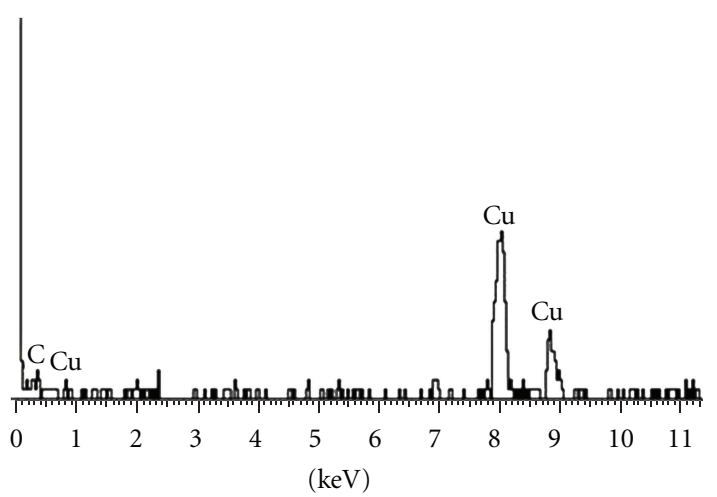

FIGURE 3: EDAX spectrum of SWCNT/Cu hybrid.

55) and XRD (Philips PANalytical X-Pert Pro diffractometer with $\mathrm{CuK} \alpha$ radiation $\lambda=0.154056 \mathrm{~nm}$ ). The nanostructure of the surfaces of SWCNTs decorated with Cu nanoparticles was confirmed by FESEM micrographs. Composition analysis of the sample was done using EDAX (JEOL JEM 2100). Raman spectra of pristine SWCNT and SWCNT/Cu hybrid structure were recorded to study the effect of the attachment of $\mathrm{Cu}$ nanoparticles on SWCNT surfaces. Raman spectroscopy was performed using LABRAM-HR800 Raman spectrometer using $514.5 \mathrm{~nm}$ Argon ion laser. To study the optical property of SWCNT/Cu hybrid, the dried sample was dispersed in dimethyl sulfoxide (DMSO) and its optical absorbance characteristics were studied using UV-Vis (Hitachi U-3010) spectrophotometer. Photoluminescence spectra were studied using a Fluorescence spectrophotometer (Perkin Elmer, LS55).

\section{Results and Discussions}

Figure 1 shows the FESEM micrograph of SWCNT/Cu nanohybrid sample. It is observed that $\mathrm{Cu}$ nanoparticles have been attached and uniformly decorated on the surfaces of SWCNT bundles.

The HRTEM micrograph of the hybrid sample is shown in Figure 2. From the micrograph, the average size of the $\mathrm{Cu}$ nanoparticles decorating the SWCNT surfaces has been calculated to be $3 \mathrm{~nm}$, using "Sigma Scan Pro 4.0" software. The Gaussian-fitted particle size distribution of $\mathrm{Cu}$ nanoparticles is shown in the inset of Figure 2.

The EDAX spectrum of SWCNT/Cu hybrid is shown in Figure 3. The EDAX spectrum clearly indicates the presence of $\mathrm{Cu}$ nanoparticles with SWCNTs $(\mathrm{C})$. The absence of oxygen $(\mathrm{O})$ at around $0.5 \mathrm{keV}$ indicates that oxide formation of the metal nanoparticles has not taken place.

Figure 4 (a) shows the XRD pattern of pristine SWCNT (i.e., the purified SWCNT) and SWCNT/Cu hybrid structure. The peaks centred at $26^{\circ}, 42^{\circ}$, and $44^{\circ}$ correspond to $\left(\begin{array}{lll}0 & 0 & 2\end{array}\right)$, ( $\left.\begin{array}{lll}1 & 0 & 0\end{array}\right)$, and ( $\left.\begin{array}{lll}1 & 0 & 1\end{array}\right)$ reflections, respectively, of the graphitic planes of the SWCNT (JCPDS card no. 75-1621). The XRD pattern of SWCNT/Cu nanohybrid gives the peaks assigned to $\left(\begin{array}{lll}1 & 1 & 1\end{array}\right)$ and $\left(\begin{array}{lll}2 & 0 & 0\end{array}\right)$ planes of cubic phase of Cu (JCPDS card no. 04-0836) along with $\left(\begin{array}{lll}0 & 0 & 2\end{array}\right)$ and ( $\left.\begin{array}{lll}1 & 0 & 1\end{array}\right)$ reflections of 


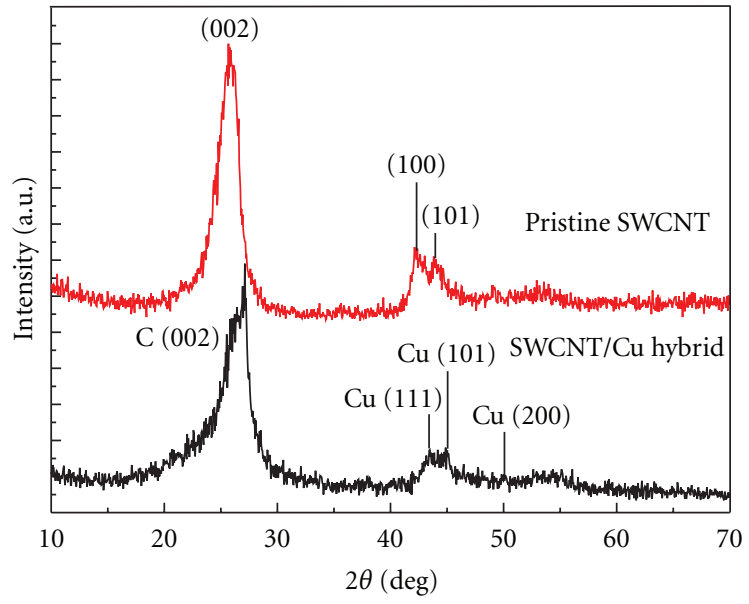

(a)

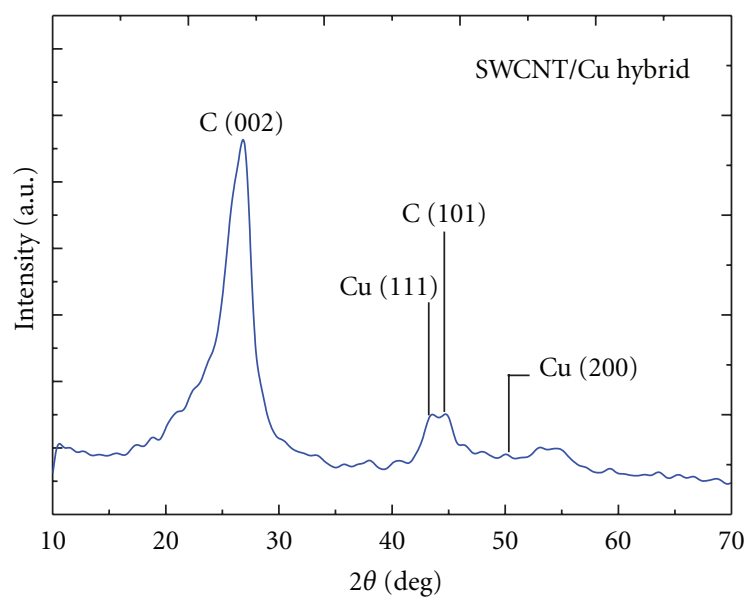

(b)

FIGURE 4: (a) XRD pattern of pristine SWCNT and SWCNT/Cu hybrid. (b) Smoothened XRD pattern of SWCNT/Cu hybrid.

the graphitic planes of SWCNTs, excluding the minor peak at $54^{\circ}$ which is a noise due to the sample holder. Figure $4(\mathrm{~b})$ shows the smoothened XRD pattern of SWCNT/Cu hybrid. The reflection planes are clearly revealed in this figure. The results thus demonstrate that $\mathrm{Cu}$ nanocrystals of cubic face centred (fcc) lattice structure have been attached onto the surfaces of SWCNT bundles.

In Figure 5, the Raman spectra of pristine SWCNT and SWCNT/Cu hybrid have been shown. $\mathrm{I}_{D} / \mathrm{I}_{G}$ factor increased on coating SWCNT bundles with $\mathrm{Cu}$ nanoparticles.

$\mathrm{I}_{D} / \mathrm{I}_{G}$ for pristine SWCNT is 0.256 , while for $\mathrm{SWCNT} / \mathrm{Cu}$ hybrid it has been found to be 0.279 . This increase in $\mathrm{I}_{D} / \mathrm{I}_{G}$ factor indicates that $\mathrm{Cu}$ nanocrystals have adhered to the SWCNT surfaces via chemical bonding [15]. The position of $\mathrm{G}$ mode of pristine SWCNT blue shifted from 1,580 to $1,591 \mathrm{~cm}^{-1}$ on decorating SWCNT walls with $\mathrm{Cu}$ nanoparticles. This blue shift indicates charge transfer between $\mathrm{Cu}$ nanoparticles and SWCNT bundles [24-26].

The UV-Vis absorption spectrum of pristine SWCNT and SWCNT/Cu hybrid is shown in Figure 6. The absorption peak position is blue-shifted by $17 \mathrm{~nm}$ on decorating $\mathrm{Cu}$

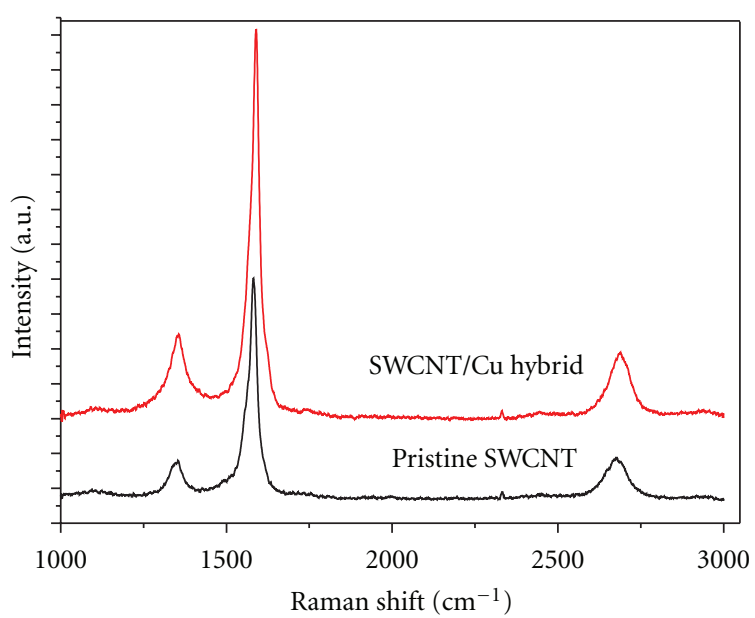

FIGURE 5: Raman spectra of pristine SWCNT and SWCNT/Cu hybrid.

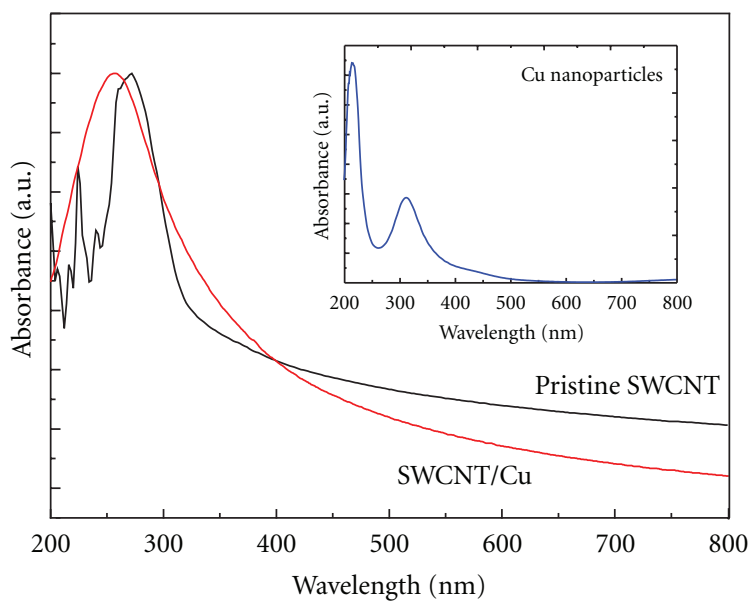

FIGURE 6: Absorption spectrum of pristine SWCNT and SWCNT/Cu hybrid; inset shows the absorption spectrum of $\mathrm{Cu}$ nanoparticles.

nanoparticles onto SWCNT walls. This blueshift may be due to the size effect of $\mathrm{Cu}$ nanoparticles. No plasmon absorption band has been recorded for the hybrid sample as reported earlier by several researchers [27].

The inset of Figure 6 shows the absorption spectrum of $\mathrm{Cu}$ nanoparticles synthesized separately using similar technique. A prominent plasmon absorption band is observed for $\mathrm{Cu}$ nanoparticles in the range of 280-350 nm with peak absorption around $320 \mathrm{~nm}$, which is greatly quenched in the case of SWCNT/Cu nanohybrid material, although appreciable absorption (with peak absorbance around $260 \mathrm{~nm}$ ) still remains up to little beyond $400 \mathrm{~nm}$. Figure 7 shows the $\mathrm{PL}$ emission from the SWCNT/Cu nanohybrid material at varying excitation wavelength from 260 to $300 \mathrm{~nm}$.

The SWCNT/Cu hybrid sample has shown broad PL emission in the range $325-500 \mathrm{~nm}$, when excited by UV radiation of wavelength varying from 260 to $300 \mathrm{~nm}$ which falls in the absorption range of the SWCNT/Cu nanohybrid. The emission from the hybrid sample is attributed to 


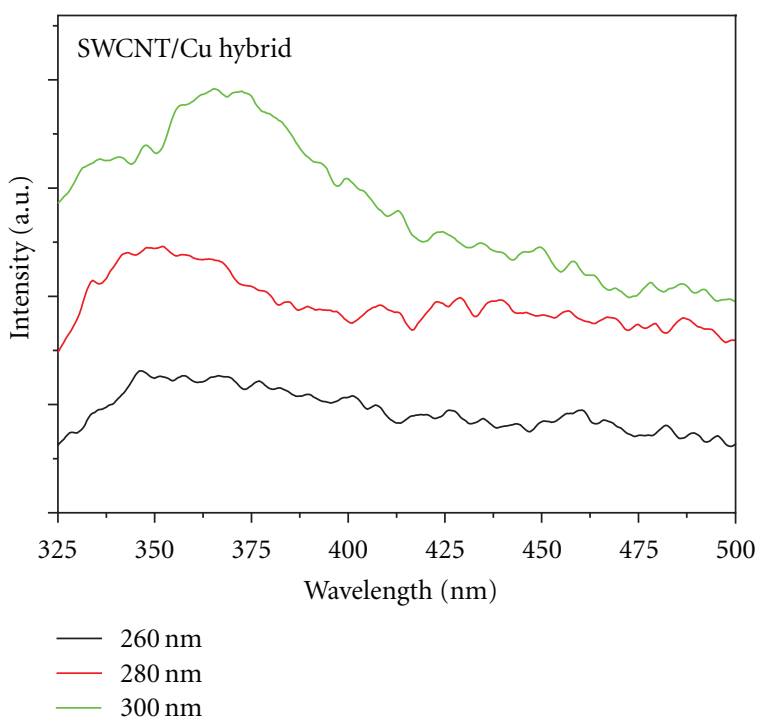

Figure 7: PL emission spectra of SWCNT/Cu hybrid at varying excitation wavelengths.

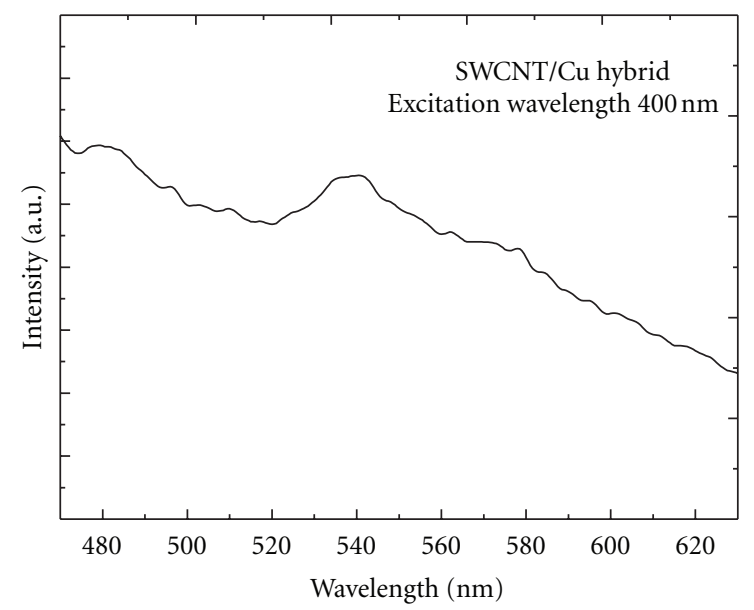

Figure 8: PL emission spectra of SWCNT/Cu hybrid at $400 \mathrm{~nm}$ excitation wavelength.

the charge transfer from $\mathrm{Cu}$ nanoparticles to SWCNTs. The emission intensity increased with the increase in excitation wavelength. This increase in PL intensity may be because of the fact that the rate of charge transfer from $\mathrm{Cu}$ nanoparticles to SWCNT bundles increased with the increase in excitation wavelength. On increasing the excitation wavelength to $400 \mathrm{~nm}$, a broad PL emission spectrum is obtained in the visible range of 480-620 nm, as shown in Figure 8. No noticeable change in emission pattern is observed although the emission intensity is appreciably enhanced. No such emission has been observed with the pristine SWCNT sample.

\section{Conclusions}

We reported a very simple chemical technique to coat SWCNT surfaces with $\mathrm{Cu}$ nanoparticles of average size $3 \mathrm{~nm}$.
The samples were characterized for their structural and compositional morphology using microscopy and spectroscopy analyses. The PL emission intensity of the nanohybrid structure increased on increasing the excitation wavelength from 260 to $300 \mathrm{~nm}$ and covered a region from 325 to $500 \mathrm{~nm}$ in the UV-visible part of the electromagnetic spectrum. When excited by a radiation of $400 \mathrm{~nm}$ wavelength, an emission spectrum in the range of 480 to $620 \mathrm{~nm}$ was observed with a peak emission around $540 \mathrm{~nm}$. Such $\mathrm{CNT} / \mathrm{Cu}$ nanohybrid material can find application in photovoltaic and solar energy conversion as well as in sensor devices.

\section{Acknowledgments}

The authors are thankful to Dr. P. Kumbhakar, Department of Physics, NIT Durgapur, for valuable discussions and cooperation. They are grateful to NIT Durgapur and Government of India for financial support. They also extend their sincere thanks to Dr. R. Mitra, IIT Kharagpur, for making the HRTEM facility available.

\section{References}

[1] M. S. Dresselhaus, G. Dresselhaus, and P. Avouris, Carbon Nanotubes: Synthesis, Structure, Properties and Applications, Springer, Berlin, Germany, 2001.

[2] M. S. Dresselhaus and H. Dai, "Carbon nanotubes: continued innovations and challenges," MRS Bulletin, vol. 29, no. 4, pp. 237-243, 2004.

[3] W. A. De Heer, "Nanotubes and the pursuit of applications," MRS Bulletin, vol. 29, no. 4, pp. 281-239, 2004.

[4] R. W. Siegel, "Synthesis and properties of nanophase materials," Materials Science and Engineering A, vol. 168, no. 2, pp. 189-197, 1993.

[5] A. P. Alivisatos, "Semiconductor clusters, nanocrystals, and quantum dots," Science, vol. 271, no. 5251, pp. 933-937, 1996.

[6] G. G. Wildgoose, C. E. Banks, and R. G. Compton, "Metal nanoparticles and related materials supported on Carbon nanotubes: methods and applications," Small, vol. 2, no. 2, pp. 182-193, 2006.

[7] M. A. Correa-Duarte and L. M. Liz-Marzán, "Carbon nanotubes as templates for one-dimensional nanoparticle assemblies," Journal of Materials Chemistry, vol. 16, no. 1, pp. 22-25, 2006.

[8] V. Georgakilas, D. Gournis, V. Tzitzios, L. Pasquato, D. M. Guldi, and M. Prato, "Decorating carbon nanotubes with metal or semiconductor nanoparticles," Journal of Materials Chemistry, vol. 17, no. 26, pp. 2679-2694, 2007.

[9] M. Penza, R. Rossi, M. Alvisi, G. Cassano, and E. Serra, "Functional characterization of carbon nanotube networked films functionalized with tuned loading of Au nanoclusters for gas sensing applications," Sensors and Actuators B, vol. 140, no. 1, pp. 176-184, 2009.

[10] Z. Liu, X. Lin, J. Y. Lee, W. Zhang, M. Han, and L. M. Gan, "Preparation and characterization of platinum-based electrocatalysts on multiwalled carbon nanotubes for proton exchange membrane fuel cells," Langmuir, vol. 18, no. 10, pp. 4054-4060, 2002.

[11] W. Li, C. Liang, W. Zhou et al., "Preparation and characterization of multiwalled carbon nanotube-supported platinum 
for cathode catalysts of direct methanol fuel cells," Journal of Physical Chemistry B, vol. 107, no. 26, pp. 6292-6299, 2003.

[12] B. J. Landi, S. L. Castro, H. J. Ruf, C. M. Evans, S. G. Bailey, and R. P. Raffaelle, "CdSe quantum dot-single wall carbon nanotube complexes for polymeric solar cells," Solar Energy Materials and Solar Cells, vol. 87, no. 1-4, pp. 733-746, 2005.

[13] I. Robel, B. Bunker, and P. V. Kamat, "SWCNT-CdS nanocomposite as light harvesting assembly: photo induced charge transfer interactions," Advanced Materials, vol. 17, no. 20, pp. 2458-2463, 2005.

[14] Y. Lin, K. A. Watson, S. Ghose et al., "Direct mechanochemical formation of metal nanoparticles on carbon nanotubes," Journal of Physical Chemistry C, vol. 113, no. 33, pp. 1485814862, 2009.

[15] Y. Lin, K. A. Watson, M. J. Fallbach et al., "Rapid, solventless, bulk preparation of metal nanoparticle-decorated carbon nanotubes," ACS Nano, vol. 3, no. 4, pp. 871-884, 2009.

[16] K. R. Reddy, B. C. Sin, C. H. Yoo et al., "A new one-step synthesis method for coating multi-walled carbon nanotubes with cuprous oxide nanoparticles," Scripta Materialia, vol. 58, no. 11, pp. 1010-1013, 2008.

[17] Q. Zhang, W. Z. Qian, H. Yu, F. Wei, and Q. Wen, "Synthesis of carbon nanotubes with totally hollow channels and/or with totally copper filled nanowires," Applied Physics A, vol. 86, no. 2, pp. 265-269, 2007.

[18] K. Chu, Q. Wu, C. Jia et al., "Fabrication and effective thermal conductivity of multi-walled carbon nanotubes reinforced $\mathrm{Cu}$ matrix composites for heat sink applications," Composites Science and Technology, vol. 70, no. 2, pp. 298-304, 2010.

[19] K. Jiang, A. Eitan, L. S. Schadler et al., "Selective attachment of gold nanoparticles to nitrogen-doped carbon nanotubes," Nano Letters, vol. 3, no. 3, pp. 275-277, 2003.

[20] R. Paul, A. Maity, A. Mitra, P. Kumbhakar, and A. K. Mitra, "Synthesis and study of optical and electrical characteristics of a hybrid structure of single wall carbon nanotubes and silver nanoparticles," Journal of Nanoparticle Research, vol. 13, no. 11, pp. 5749-5757, 2011.

[21] Y. Shi, R. Yang, and P. K. Yuet, "Easy decoration of carbon nanotubes with well dispersed gold nanoparticles and the use of the material as an electrocatalyst," Carbon, vol. 47, no. 4, pp. 1146-1151, 2009.

[22] G. S. Duesberg, M. Burghard, J. Muster, G. Philipp, and S. Roth, "Separation of carbon nanotubes by size exclusion chromatography," Chemical Communications, no. 3, pp. 435-436, 1998.

[23] S. Bandow, A. M. Rao, K. A. Williams, A. Thess, R. E. Smalley, and P. C. Eklund, "Purification of single-wall carbon nanotubes by microfiltration," Journal of Physical Chemistry B, vol. 101, no. 44, pp. 8839-8842, 1997.

[24] R. Graupner, "Raman spectroscopy of covalently functionalized single-wall carbon nanotubes," Journal of Raman Spectroscopy, vol. 38, no. 6, pp. 673-683, 2007.

[25] A. M. Rao, P. C. Eklund, S. Bandow, A. Thess, and R. E. Smalley, "Evidence for charge transfer in doped carbon nanotube bundles from raman scattering," Nature, vol. 388, no. 6639, pp. 257-259, 1997.

[26] G. U. Sumanasekera, J. L. Allen, S. L. Fang, A. L. Loper, A. M. Rao, and P. C. Eklund, "Electrochemical oxidation of single wall carbon nanotube bundles in sulfuric acid," Journal of Physical Chemistry B, vol. 103, no. 21, pp. 4292-4297, 1999.

[27] M. Scarselli, P. Castrucci, L. Camilli et al., "Influence of $\mathrm{Cu}$ nanoparticle size on the photo-electrochemical response from $\mathrm{Cu}$-multiwall carbon nanotube composites," Nanotechnology, vol. 22 , no. 3 , article 035701,9 pages, 2011. 

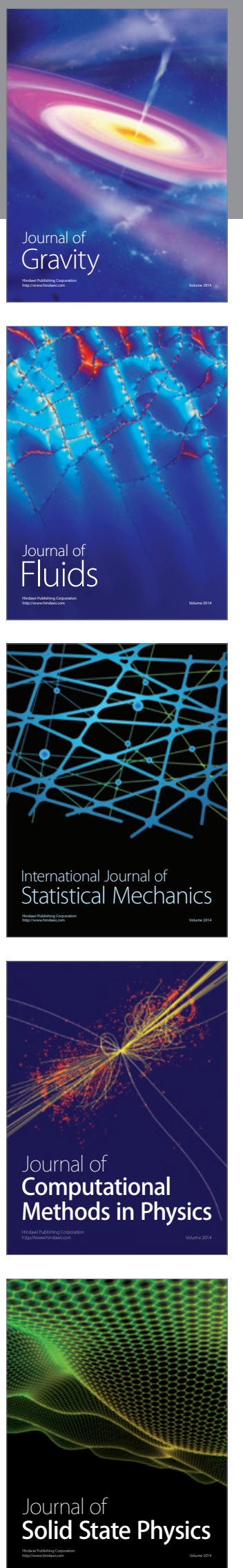
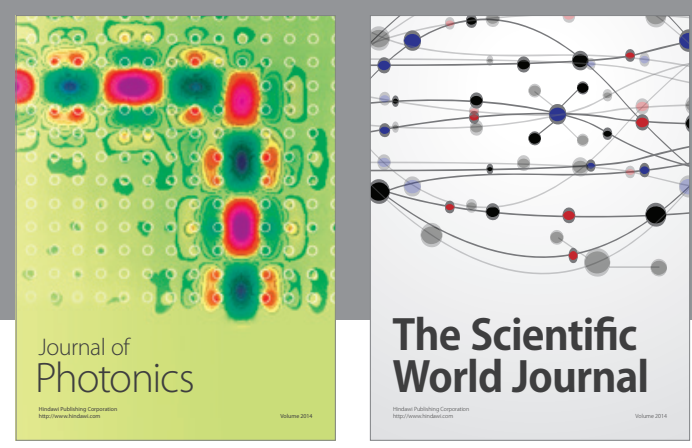

The Scientific World Journal

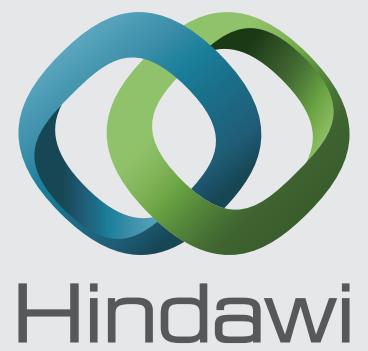

Submit your manuscripts at http://www.hindawi.com
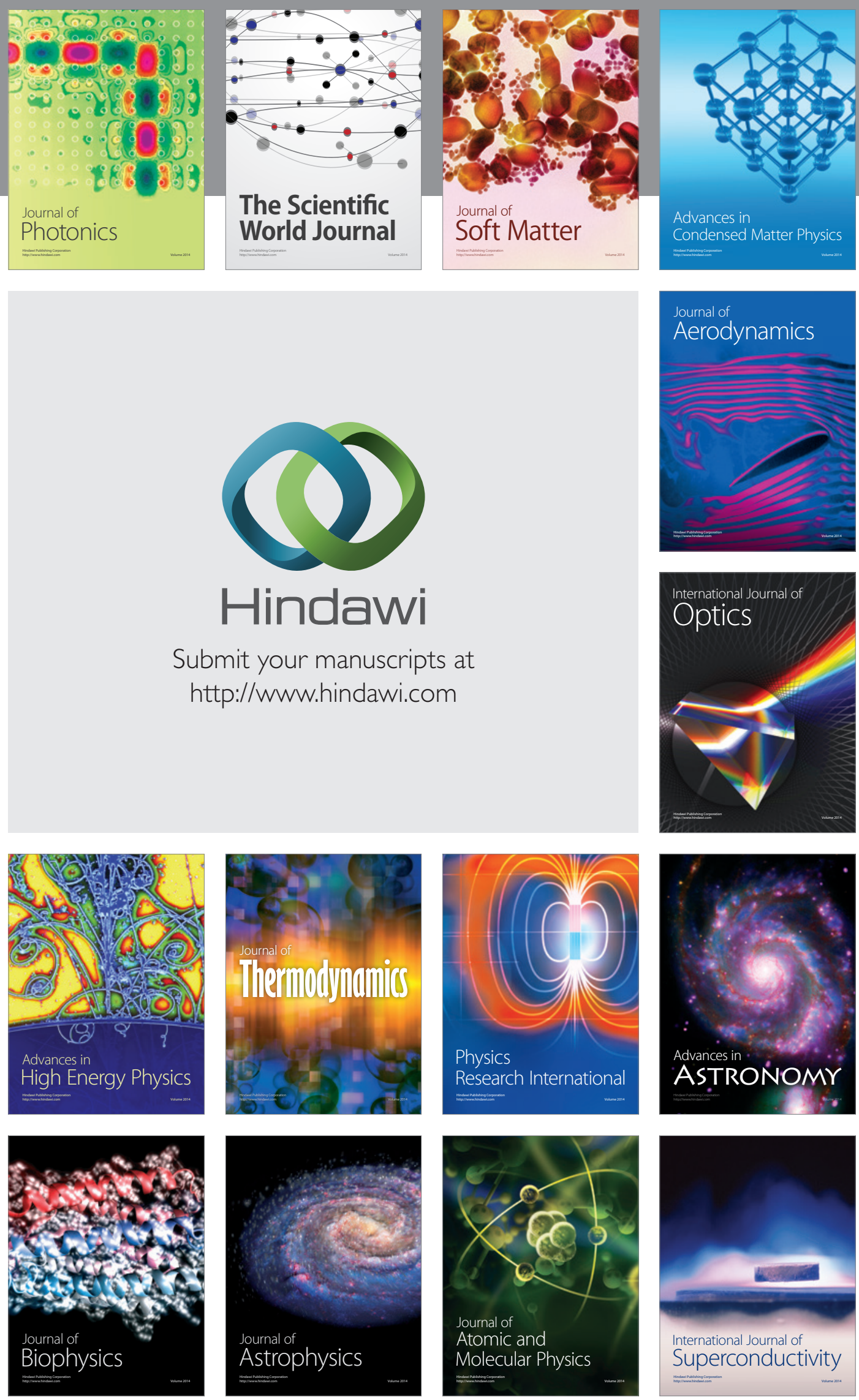
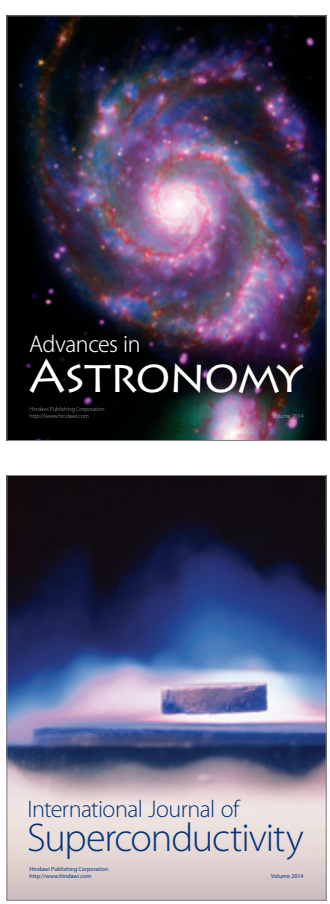